\title{
Improving treatment and outcomes for young people with fetal alcohol spectrum disorder in the youth justice system: A social work led response and practice framework
}

\author{
Vanessa Oatley and Anita Gibbs, University of Otago, New Zealand
}

\begin{abstract}
INTRODUCTION: Young people with fetal alcohol spectrum disorder (FASD) in Aotearoa New Zealand are both primed for, and hindered within the youth justice (YJ) system. This research provides a fresh perspective on how social workers can take a lead role in ensuring young people with FASD receive neurodevelopmentally appropriate interventions both within the YJ system and upon return to their communities.
\end{abstract}

METHODS: A systematic literature review of secondary data was undertaken to explore themes, including the connection between the impacts of FASD and risk of contact with the YJ system; how FASD affects the young person's ability to navigate the $\mathrm{YJ}$ system; best practice recommendations to ensure just treatment for young people in the $\mathrm{YJ}$ system; and the potential for social work to take a lead role in improving treatment and outcomes for young people with FASD in the YJ system.

FINDINGS: Key findings include the confirmation of the link between young people with FASD and the YJ population; consistent best practice recommendations for treatment and interventions; and a clear positive relationship between the social work mandate and the implementation of the recommended treatment for young people with FASD who have had contact with the YJ system.

PRACTICE IMPLICATIONS: Based on the research findings, an FASD-informed practice framework has been developed as a tool to guide social workers who are working with young people with FASD in the Aotearoa New Zealand YJ system and beyond.

KEYWORDS: Fetal alcohol spectrum disorder; FASD; youth; rangatahi; youth justice; social work

\section{FASD overview: Definition, diagnosis, and prevalence}

It is now universally accepted in the research literature that exposure to alcohol during pregnancy is the leading cause of permanent neurological impairment to the developing brain, and that it has significant and lifelong impacts (Astley, 2011; Crawford, 2018; Enns \& Taylor, 2018). The term fetal alcohol spectrum disorder (FASD) is the currently accepted diagnostic term to capture the broad spectrum of presentations that can occur as a result
AOTEAROA NEW ZEALAND SOCIAL WORK 32(2), 5-16.

CORRESPONDENCE TO: Vanessa Oatley veeoatley@gmail.com 
of damage to the central nervous system due to pre-natal alcohol exposure (PAE) (Carpenter, Blackburn, \& Egerton, 2014; Cook et al., 2016; Enns \& Taylor, 2018). The term FASD has replaced other commonly used descriptors such as fetal alcohol syndrome (FAS), partial fetal alcohol syndrome (pFAS), and alcohol-related neurodevelopmental disorder (ARND).

The primary physical, social, cognitive, and behavioural impairments of FASD are well documented and largely agreed upon by researchers and professionals (Mattson, Crocker, \& Nguyen, 2011; Streissguth \& O'Malley, 2000), as is the understanding that different impairments present at different developmental stages throughout the lifespan (Carpenter et al., 2014; Salmon, 2014). These primary impairments are highly likely to lead to secondary conditions during the lifespan of those with FASD, which might include school exclusions, trouble with the law, mental health issues, care experience, substance misuse and suicide attempts (Streissguth et al., 2004).

The task of gaining a firm diagnosis of FASD is complicated by the myriad of presenting primary impacts (Chudley, 2018), as well as the similarity of the FASD phenotype to other disorders such as attention deficit hyperactivity disorder, autism, attachment disorder, dyspraxia, learning difficulties, auditory and visual processing issues, and conduct disorder (Brown \& Mather, 2014; Gibbs \& Sherwood, 2017). Despite these evident hurdles, the importance of a sound diagnosis of FASD cannot be overstated. From a public health perspective, diagnostic misclassification can lead to inaccurate data collection regarding the incidence and prevalence of FASD, thus limiting appropriate resourcing and reducing reliability of measurement data based on prevention efforts. From a clinical perspective, misdiagnosis can generate inappropriate interventions, and ignore the potential development of secondary risk factors (Astley, 2011; Brown \& Mather, 2014).
The best tool for identifying FASD in any child or young person is an accurate history of maternal prenatal alcohol consumption (Chudley, 2018; Cook et al., 2016). In the absence of a PAE history, a diagnosis can be assigned when the specific facial phenotype is evident (short palpebral fissure-small eyes, smooth philtrum, and a thin vermillion border on the upper lip): the presence of this unique facial phenotype confirms that an individual was affected, at least in part, by PAE (Astley, 2011). It is important to note, however, that occurrence of all three sentinel facial features have been evidenced in less than $4 \%$ of diagnosed cases of FASD (Clarren et al., 2015).

In Aotearoa New Zealand, there is a clinical consensus to use the Canadian guidelines of Cook et al. (2016) in the absence of a unique national set. Canadian guidelines require severe central nervous system impairment in a minimum of three of these domains: "motor skills; neuroanatomy; neurophysiology; cognition; language; academic achievement; memory; attention; executive function, including impulse control and hyperactivity; affect regulation; and adaptive behaviour, social skills or social communication" (Cook et al., 2016, p. 193). Diagnosis requires the young person to undertake a medical examination (Cook et al., 2016) followed by a neurodevelopmental assessment utilising a multi-disciplinary approach with a team of professionals from a variety of disciplines, including any of the following: medicine, psychology, developmental paediatrics, speech-language, occupational therapy, education, and social work (Chudley, 2018; Cook et al., 2016).

Prevalence rates of FASD are a source of vigorous debate due to the complex nature of the diagnostic process, the lack of collected or recorded data, and the potential for misdiagnosis (Carpenter et al., 2014). The most recent study out of the United Kingdom by McQuire et al. (2019) $(n=13,495)$ estimated FASD screening prevalence of between $6 \%$ and $7.2 \%$, 
and the most recent American research by May et al. $(2018)(n=13,146)$ peaks at $9.9 \%$. Aotearoa New Zealand has no established prevalence data, thus international prevalence estimates are generally applied (Connor \& Casswell, 2012; Crawford, 2018; Gibbs \& Sherwood, 2017). These estimates are most likely very low as Fitzpatrick et al. (2017) points out-higher prevalence of FASD occurs in communities where binge drinking, poverty, and geographical isolation intersect. This creates somewhat of a perfect storm in Aotearoa New Zealand-a geographically isolated country, with clear pockets of poverty and deprivation, and a binge drinking culture that continues to pose serious risks to society (Cheung, Timmins, \& Wright, 2015; Mallard, Connor, \& Houghton, 2013; Salmon, 2014).

If we take the lowest range of the United Kingdom FASD prevalence data of $6 \%$ and apply it to Aotearoa New Zealand, then around 3,600 children affected by PAE would be born each year. Given that it is widely acknowledged that FASD is underrecognised and PAE is under-reported (Connor \& Casswell, 2012; Crawford, 2018; Rogan \& Crawford, 2014), the final figure of births affected by PAE in Aotearoa New Zealand could be substantially higher than international norms.

\section{Primed for the youth justice system}

Young people with FASD are predisposed to a broad range of difficulties, the dominant issue for adolescents being the general impairment in adaptive functioning that occurs through a combination of deficits in both executive functioning and social cognition, and presents as cognitive and neurodevelopmental sequelae that can lead to contact with the YJ system and affect interactions within the system (Bower et al., 2018; Crawford, 2018; Killingley, 2014).

Deficits in executive functioning such as impaired memory, and difficulty composing rational, logical thoughts (Brown \& Mather,
2014; Gibbs \& Sherwood, 2017; Lynch, 2016)

can manifest as poor judgement, a lack of understanding of cause and effect, or actions and consequences, and confusion over abstract concepts such as ownership and time (Egerton, 2014; Fast \& Conry, 2004; Gibbs \& Sherwood, 2017; McIver, 2010b). These difficulties can result in offending behaviour that can seem illogical to the bystander, and the young person may struggle to understand the seriousness of a situation (McIver, 2010b).

Poor impulse control and emotional lability are also associated with FASD and can contribute to young people finding themselves in trouble with the law (Fast \& Conry, 2004; Killingley, 2014; McIver, 2010b). It does not require much imagination to conceive of the potential for criminal behaviour when you couple an inability to control impulses with poor habituation, often presenting as rapid swings in mood (Salmon, 2014). Add to that a heightened fight or flight response in high stress situations (Killingley, 2014), a tendency to sensory overload (Lynch, 2016; McIver, 2010b) and susceptibility to adverse psychosocial influences such as peer pressure (Crawford, 2018; Egerton, 2014; Hughes \& Peirse O'Byrne, 2016; Salmon, 2014) and it is clear that young people with FASD have increased vulnerability for involvement in the criminal justice system.

In addition, the propensity to confabulate associated with FASD can lead young people to construct fanciful fabricated stories, sometimes combining real events with memories or ruminations (Brown \& Mather, 2014) and to be highly suggestible, tending to acquiesce and adjust their responses according to external feedback (Brown, Gudjonsson, \& Connor, 2011; Killingley, 2014). This high level of suggestibility can result in false confessions and young people being wrongly convicted (Killingley, 2014).

Pei, Leung, Jampolsky, and Alsbury (2016) highlight the double jeopardy for young 
people with FASD where vulnerabilities such as social stigma; exclusion from education; and lack of support in health and welfare systems (Egerton, 2014; Gibbs \& Sherwood, 2017; Hughes \& Peirse O'Byrne, 2016; Mattson et al., 2011) are compounded by adverse environmental factors such as a history of abuse; disrupted education; poverty; contact with the state care system and complex trauma (Bower et al., 2018; Fast \& Conry, 2009; Hughes, Williams, Chitsabean, Davies, \& Mounce, 2012; Walker, 2018). Added to these, youth with FASD often have comorbid diagnoses of mental health issues including depression, anxiety, ADHD, conduct disorder and alcohol and drug addiction (Fast \& Conry, 2009; Salmon, 2014).

In Aotearoa New Zealand, the intersection between the FASD population and the YJ population is largely acknowledged (Gibbs \& Sherwood, 2017; Lynch, 2016; Rogan \& Crawford, 2014; Salmon, 2014); however, there have been no local prevalence studies undertaken to date (Lynch, 2016; Rogan \& Crawford, 2014). One of the most commonly cited studies into the prevalence of FASD in the justice population was undertaken by Fast, Conry, and Loock (1999) $(n=287)$ in a Canadian youth forensic psychiatric unit. The study found that $23.3 \%$ of the participants had evidence of FASD. Hughes et al. (2012) also completed an extensive report on the prevalence of neurodisability in young people who offend, and identified prevalence rates in the range of $10.9-11.7 \%$ (Hughes \& Peirse O'Byrne, 2016). A more recent study by Bower et al. (2018) undertaken in Western Australia $(n=99)$ found that $36 \%$ of the young people assessed had FASD. The three studies outlined here demonstrate extremely high ratios of justice system contact for young people with FASD when compared to the general population.

\section{Hindered within the $\mathrm{YJ}$ system}

There are multiple areas of concern regarding the possible treatment and outcomes for young people with FASD within the current Aotearoa New Zealand YJ system. Firstly, the literature is clear that there is limited understanding of FASD across the entire $\mathrm{YJ}$ system, including police, judges, legal professionals, and social workers (Fast et al., 1999; Gralton, 2014; Lynch, 2016; Townsend, Hammill, \& White, 2015). There is a continued reliance on traditional assumptions about young offenders' behaviour which does nothing to account for neurodevelopmental impairments such as FASD (Fitzgerald, 2015; McIver, 2010b). This lack of knowledge is further exacerbated by a lack of collaboration between services including justice, health, social development and education (Lynch, 2016).

The second area of concern is the use of youth detention or custodial placements. Without well informed professional guidance, custodial placements can leave young people: struggling to understand the rules, being open to victimisation, exploitation, and abuse, and susceptible to the negative influences of their peers in an effort to fit in (Fast \& Conry, 2009; Gralton, 2014; Lynch, 2016). Likewise, being held for any duration in police custody or solitary confinement can aggravate FASD presentations, particularly from a sensory perspective with bright lights and small lock-up rooms causing additional stress (Lynch, 2016).

The strict sanctions and punitive measures widely employed in the justice system present another problematic area as they are considered to be ineffective for young people with FASD (Fitzgerald, 2015; Gralton, 2014; Lynch, 2016). Such approaches assume the brain can understand the concept of consequences, along with cause and effect; in short, they assume the young person with FASD can learn their lesson when in many cases the deficits in executive functioning derail that assumption (Gralton, 2014; Lynch, 2016). Whilst it is essential to ensure young people are held accountable for harm to 
the victims of their crimes (Lynch, 2016), critical to the pursuit of this accountability is tailoring the response to reflect the presence of neurological impairment (Fast \& Conry, 2009).

The dominant use of diversion and FGCs in the Aotearoa New Zealand YJ system poses significant risks for young people with FASD (Fitzgerald, 2015). Decisions about diversion and at FGCs are often made without any legal representation for the young person, and in the case of FGCs, there is a reliance on the young person's ability to understand what is expected of them, communicate their needs, avoid the inclination to confabulate, and effectively communicate remorse to victims and families (Lynch, 2016). The preference for diversion and FGCs over formal court appearances can in some cases signal a missed opportunity for engagement, diagnostic screening, and FASD assessment (Lynch, 2016).

Language plays a fundamental role in the legal system both in written and oral forms and young people with FASD often present with language deficits (Tavioni-Pittman \& Marsh, 2017). Delayed language processing and comprehension can leave young people vulnerable to manipulation and entrapment; inability to communicate can draw incorrect assumptions from observers, such as interpreting short answers or no response as petulance, or conversely if the young person with FASD is superficially articulate (Brown \& Mather, 2014). These factors can lead to false assumptions about overall competence and reduce opportunities for assistance (Tavioni-Pittman \& Marsh, 2017).

\section{Best practice treatment recommendations and desired outcomes}

Several key recommendations that could be adopted to improve treatment and consequently outcomes for young people with FASD in the $\mathrm{YJ}$ system emerged from the research.
Many commentators cite a lack of knowledge of the impacts of FASD as a barrier to optimal service provision (Bower et al., 2018; Fitzgerald, 2015; Killingley, 2014; Pei et al., 2016), and suggest a focus on building a skilled and supported workforce through training, education, and professional development, as well as provision of appropriate resources (Bower et al., 2018). Raising the profile of FASD within the Aotearoa New Zealand YJ system would increase the possibility of FASD characteristics being identified and the necessary accommodations being made (Lynch, 2016; Pei et al., 2016).

Experts in the FASD YJ field argue for mandatory comprehensive screening for neurodevelopmental impairment of all youth in contact with the justice system in Aotearoa New Zealand (Fitzgerald, 2015; JustSpeak, 2012; Lynch, 2016). Diagnostic screening would identify individuals who are suspected of having FASD and enable them to be referred for comprehensive diagnostic assessment. Closely linked to diagnostic screening is the recommendation to employ vigorous methods of evaluation of both the capacity and culpability of young people with FASD (Fitzgerald, 2015; Hughes \& Peirse O'Byrne, 2016; Longstaffe et al., 2018). Fitzgerald (2015) contends that the best way to uphold the interests of both the community and the victims affected by youth crime is to identify the true impetus for the offending behaviour and address this fully in order to prevent reoffending. In the case of FASD, evaluations need to be person-specific, include potential risks and protective factors, with sentencing linked to each individual's capacity and culpability (Fast \& Conry, 2009; McIver, 2010a).

Taking a long-term, individualised view of the treatment, planning, and support of young people with FASD in the YJ system is critical to successful outcomes. Planning should be strengths based and done in tandem with the young person and their parents or caregivers to ensure client direction, voice, and ownership 
(Longstaffe et al., 2018). Community based capacity and support networks need to be developed with the young person in mind and professional networks of services need to be coordinated and available outside the justice setting (Brown, Connor, \& Adler, 2012). This wrap-around support and coordinated service delivery should benefit not only the young person, but the parents or caregivers, and the wider community (Crawford, 2018; Lynch, 2016).

Both the overrepresentation of Māori youth in justice statistics (Becroft, 2017; Walker, 2018) and a commitment to te Tiriti o Waitangi call for Aotearoa New Zealand responses to young people with FASD in the YJ system to be aligned with a te ao Māori approach, to recognise the significance of te reo Māori, and to incorporate Māori models of practice (Crawford, 2018). Durie (2001) reminds us that whānau- or caregiverbased interventions play an essential part in culturally responsive work with Māori and that whānau is not limited to blood relatives, thus individuals with a close connection to the young person should also be included in the whānau network (Crawford, 2018).

\section{Why social work?}

In Aotearoa New Zealand, social workers, across both State agencies and NGOs, work extensively with youth with FASD, even when diagnoses may not have occurred. The research indicates that approximately $50 \%$ of children and young people in the care of Oranga Tamariki are affected by FASD (FASD Working Group, 2016). It is highly likely that young people with FASD who are in contact with the YJ system have been subject to interventions from social services throughout their young lives, with social workers playing a key role in many of these interactions and holding a uniquely privileged view across a young person's environments (Badry \& Choate, 2015). Furthermore, in many cases, the social worker will have an established position and relationship in the lives of young people with FASD and their families or caregivers (Badry \& Choate, 2015; Popova, Lange, Bekmuradov, Mihic, \& Rehm, 2011). It is therefore important that social workers respond and work appropriately with youth who have, or are suspected to have, FASD.

The International Federation of Social Workers (IFSW, 2014) provides this definition of social work:

Social work is a practice-based profession and an academic discipline that promotes social change and development, social cohesion, and the empowerment and liberation of people. Principles of social justice, human rights, collective responsibility and respect for diversities are central to social work. Underpinned by theories of social work, social sciences, humanities and indigenous knowledge, social work engages people and structures to address life challenges and enhance wellbeing. (para. 1)

There are clear markers within this international definition that point towards a natural fit between the social work mandate and the work required with young people with FASD in the YJ system.

The obligation to promote "social change and development, social cohesion, and the empowerment and liberation of people" (IFSW, 2014, para. 1) aligns with the recommendation to raise the profile of FASD through training and education (Fitzgerald, 2015; Gibbs et al., 2020; Longstaffe et al., 2018). The commitment to uphold the "principles of social justice, human rights, collective responsibility and respect for diversities" (IFSW, 2014, para. 1) demands that social workers view FASD within the recommended human rights, indigenous rights, and disability rights frameworks (Townsend et al., 2015).

The presence of "collective responsibility" (IFSW, 2014, para. 1) within the definition speaks to the notion of collaboration 
with multi-disciplinary teams, the young person, and the family or caregivers, from assessment to diagnosis to treatment both within the $\mathrm{YJ}$ system and across the lifespan (Astley, 2011; Chudley, 2018; Cook et al., 2016; Lynch, 2016; McIver, 2010b). Further, the call to "engage people and structures to address life's challenges and enhance wellbeing" (IFSW, 2014, para. 1) would clearly benefit young people and their families who are experiencing the challenges of living with FASD whilst simultaneously navigating the YJ system. The professional mandate of the social worker demands that they engage with, advocate for, and appropriately resource young people to address the challenges presented by their neurodevelopmental disability.

In addition, the code of ethics of the Aotearoa New Zealand Association of Social Workers (ANZASW, 2015) provides further indicators to substantiate the hypothesis that social work would be well placed to take a lead role in improving treatment and outcomes for young people with FASD within the YJ system. The first ethical responsibility outlined is for a te Tiriti o Waitangi based society, and the key aspects as they relate to rangatahi with FASD and their whānau or caregivers are: ensuring that, at all times, the imposition of mono-cultural values and concepts are avoided; promoting the use of Tāngata Whenua social work models of practice; and being actively anti-racist (ANZASW, 2013). Given the overrepresentation of Māori youth in justice statistics (Becroft, 2017; Walker, 2018) it is self-evident that social workers working with rangatahi with FASD and their whānau or caregivers in the YJ system need to be determinedly practising to protect the integrity of Tāngata Whenua.

An ethical responsibility to the wider community is also part of the social work mandate (ANZASW, 2013), specifically the principles of inclusion and choice for all members of society, with particular regard for disadvantaged minorities, including preventing discrimination based on psychological and physical abilities (ANZASW, 2013). A further component of this ethical obligation addresses the need to promote the fair allocation of community resources (ANZASW, 2013), and provides a strong basis for the argument for increased diagnostic tools and screening processes, along with adequately resourced support systems. The ethical obligation to clients within the ANZASW code clearly outlines the responsibility of the social worker to respect the dignity and worth of each individual client, to protect the client's rights and welfare and to encourage self-determination (ANZASW, 2013), all of which underpin one of the key recommendations for individualised, inclusive, long-term, strengths-based practice (Badry \& Choate, 2015; FASD Working Group, 2016; Malbin, 2002).

The above discussion has clearly outlined the expectations of the social worker, both by definition and from an ethical standpoint, as well as highlighted the existing role that social workers play in the lives of many families affected by the impacts of FASD. It is clear that a social work led response which incorporates best practice for, and treatment of, young people with FASD in the YJ system could ameliorate many of the negative impacts of the current YJ system and improve outcomes overall.

\section{Using an FASD-informed practice framework for social work in the youth justice system}

There is an old adage that proclaims theory without practice is meaningless, but practice without theory is blind. It is this sentiment that provides the impetus for the creation of a theoretical practice framework (Figure 1) to scaffold the how to of social work taking a lead role in improving treatment and outcomes for young people with FASD in the YJ system. 


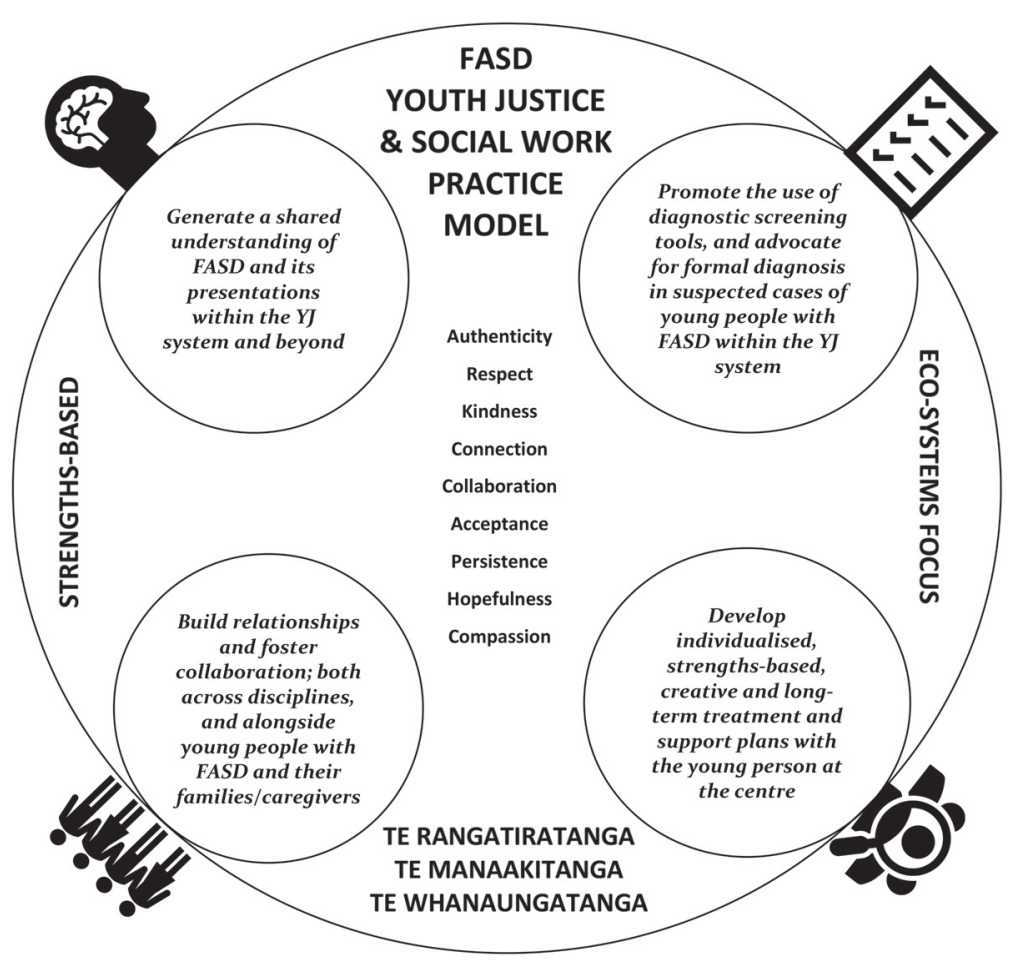

Figure 1. FASD-informed practice framework for social work in the YJ system.

This practice framework is underpinned by dual theoretical perspectives, the strengths perspective as prescribed by Saleebey (1997), and the ecological systems approach as recommended by Ungar (2014). Employing a strengths-based theoretical perspective is an attempt to ameliorate the deficit focus which is particularly apparent in the $\mathrm{YJ}$ system where young people are often considered naughty, wilful, and delinquent (Egan \& Craik, 2016). The ecological systems approach ensures that the response to FASD within the $\mathrm{YJ}$ system focuses on the young person within their environment (Ungar, 2014).

The social work commitment to te Tiriti o Waitangi is a fundamental expectation of all social work professionals and a critical underpinning principle of this framework. The partnership founded in te Tiriti o Waitangi calls for all social workers to demonstrate indigenous and bicultural practices in their work. Social work professionals are provided with the Kaitiakitanga framework (Tāngata
Whenua Voices in Social Work, 2016) which informs the assessment of a social workers competence to work with Tāngata Whenua. Competency is assessed through the demonstrated application of three applied principles - te rangatiratanga; te manaakitanga; and te whanaungatanga (Tāngata Whenua Voices in Social Work, 2016). It is beyond the scope of this work to detail fully the Kaitiakitanga framework principles, however, it is implied that the principles are embedded within the execution of this theoretical practice framework.

Another key component of the theoretical practice framework includes the personal attributes the social worker brings to the work. The research based personal attributes necessary to work effectively within the FASD-affected community have been summarised as authenticity; acceptance; persistence; maintaining a hopeful outlook; being compassionate (Matua Raki, 2019); and thinking creatively (Badry \& Choate, 2015; Malbin, 2002).

Like other local and international frameworks for working with individuals and families with FASD, this FASD-informed practice framework highlights the role of the social worker as an agent of change (Bagley, 2019; Gibbs et al., 2020) and identifies four key skills components for the social worker to incorporate into work alongside young people with FASD.

The first key skills component is to generate a shared understanding of FASD and its presentations within the $Y J$ system and beyond. A recurring theme throughout the literature has been FASD-based knowledge dissemination (Bagley, 2019; Bower et al., 2018; Fitzgerald, 2015). Implementation of training, education, and knowledge sharing will increase awareness of FASD as a neurological disability with behavioural symptoms, and contribute to minimising the stigma attached to FASD, debunking common myths, and resulting in a better understanding of the causes of youth offending. 
The second key skills component focuses on the development and implementation of diagnostic screening tools and advocating for formal diagnosis in suspected cases of young people with FASD within the YJ system. The research findings clearly identified the issue of the high numbers of undiagnosed or misdiagnosed young people with FASD in the YJ system (Gralton, 2014; Killingley, 2014; Popova et al., 2011) and, despite the implementation of screening tools being a key recommendation within the literature on best practice, Aotearoa New Zealand currently has none. It is clear that this is an area that needs addressing with urgency.

Once a suspected case of FASD is reported, the social worker will likely be required to advocate for a formal diagnosis for the young person. In the advocacy role it will be essential for the social worker to be able to evidence the reasons why a diagnosis is important as they may encounter push-back from professionals who either believe that a confirmed diagnosis will only increase the impact of stigma (Payne et al., 2011; Tough, Clarke, \& Hicks, 2003) or see little point in a diagnosis that has either minimal or no resourcing attached (Crawford, 2018). Ironically, this lack of resourcing is directly related to the paucity of formally diagnosed cases of FASD (Astley, 2011).

The third key skills component is to build relationships and foster collaboration; both across disciplines and alongside young people with FASD and their families or caregivers. This collaborative approach is widely recommended in the literature (Bagley, 2019; FASD Working Group, 2016; Gibbs et al., 2020; Lynch, 2016; Matua Raki, 2019) and places an emphasis on all stakeholders involved. This is the social worker's opportunity to implement a collaborative case-management approach, coordinating the various speciality services, along with input from the young person, family or caregiver to navigate the critical nexus between assessment and action (Badry \& Choate, 2015). Employing a collaborative approach enables the social worker to build working relationships that ensure consistency; access collective wisdom to develop a robust and appropriate plan; acknowledge young people and families as experts in their own lives; and more effectively and appropriately wrap support around young people with FASD, and their families (Gibbs et al., 2020).

The final key skills component is developing individualised, strengths-based, creative and long term treatment and support plans with the young person with FASD and their family or caregivers firmly at the centre. It is recognised throughout the literature that the conversation around young people with FASD remains stubbornly focused on containment strategies, be they physical, diagnostic, behavioural, or epidemiological (Badry \& Choate, 2015). This key skills component redirects that conversation and bases the planning firmly around the strengths and challenges of each individual young person (Badry \& Choate, 2015; FASD Working Group, 2016; Malbin, 2002).

The FASD-informed practice framework aims to support the social worker to achieve the desired outcomes: avoiding recidivism by prioritising rehabilitation and reintegration (Gibbs \& Sherwood, 2017; Lynch, 2016; Popova et al., 2011); enhancing the wellbeing and life chances of the young person with FASD (Ontario Centre of Excellence for Child and Youth Mental Health, 2016); and subsequently improving overall community safety (Fitzgerald, 2015; Lynch, 2016).

It is important to note that the practice framework is untested and, although based on international frameworks and evidencebased best practice recommendations, it requires field testing and assessment to ensure praxis can occur.

\section{Conclusion}

It has been established that working with young people with FASD within the YJ system is complex, cross-sector work, however, a clear connection has been drawn between the social work 
professional mandate and the best practice recommendations for the treatment of young people with FASD in the YJ system. This connection provides sufficient evidence to conclude that a social work led response could make a significant positive difference to the treatment and outcomes for young people with FASD involved in the YJ system by assisting young people, their families or caregivers and other professionals to navigate the complex terrain that unfolds as a product of invisible disability (Badry \& Choate, 2015; Gibbs et al., 2020).

In the last 20 years, awareness of FASD has increased exponentially with the brave and dedicated work of a number of key stakeholders: professionals, and families and caregivers (Gibbs \& Sherwood, 2017). Despite this increase in awareness, FASD remains a highly complex and underacknowledged issue in Aotearoa New Zealand (Badry \& Choate, 2015) and there is a clear need for more research in this area (FASD Working Group, 2016).

In addition to the practical work at the coalface for social workers, a broader theme emerged from this research. This overarching theme captures the need for a paradigm shift when working with young people with FASD (Gillen \& Dubovsky, 2012; Malbin, 2002; Walker, 2018). If we are to avoid further injustice for young people with FASD, we must ensure that each individual young person is able to engage in a neurodevelopmentally appropriate way in the whole YJ process. We must move away from the focus on the young person with FASD as the problem, and support exchanges within the YJ system that consider the wider internal and external impacts on each individual young person. Working towards the fulfilment of these goals is where social workers can play a lead role to support young people with FASD in the YJ system to reclaim a more positive future.

Accepted 14 April 2020

Published 1 August 2020

\section{References}

Aotearoa New Zealand Association of Social Workers. (2015). The code of ethics of the Aotearoa New Zealand Association of Social Workers. Retrieved from https://anzasw.nz/wp-content/uploads/COE-for-websitechapter-3.pdf

Astley, S. J. (2011). Diagnosing fetal alcohol spectrum disorders (FASD). In S. A. Adubato \& D. E. Cohen (Eds.), Prenatal alcohol use and fetal alcohol spectrum disorders: Diagnosis, assessment and new directions in research and multimodal treatment (pp. 3-29). Retrieved from http://depts.washington.edu/fasdpn/pdfs/astleyFASD-chapter2011.pdf

Badry, D., \& Choate, P. (2015). Fetal alcohol spectrum disorder: A disability in need of social work education, knowledge and practice. Social Work and Sciences Review, 17(3), 20-32. Retrieved from https:/cwrp.ca/publications/fetal-alcohol-spectrumdisorder-disability-need-social-work-educationknowledge-and

Bagley, K. (2019). Responding to FASD: What social and community service professionals do in the absence of diagnostic services and practice standards. Advances in Dual Diagnosis, 12(1/2), 14-26. Retrieved from https://www.emeraldinsight.com/doi/abs/10.1108/ ADD-05-2018-0007

Becroft, A. (2017). Fulfilling the vision: Improving family group conference preparation and participation. Retrieved from http://www.occ.org.nz/publications/ reports/state-of-care-2017-family-group-conferences/

Bower, C., Watkins, R. E., Mutch, R. C., Marriott, R., Freeman, J., Kippin, N. R., ... Giglia, R. (2018). Fetal alcohol spectrum disorder and youth justice: $A$ prevalence study among young people sentenced to detention in Western Australia. BMJ open, 8(2), 1. Retrieved from https://www.ncbi.nlm.nih.gov/ pubmed/29440216

Brown, J., \& Mather, M. (2014). Foetal alcohol spectrum disorders: Parenting a child with an invisible disability. Oxford, UK: FASD Trust.

Brown, N., Connor, P. D., \& Adler, R. S. (2012). Conductdisordered adolescents with fetal alcohol spectrum disorder: Intervention in secure treatment settings. Criminal Justice and Behavior, 39(6), 770-793. Retrieved from https://journals.sagepub.com/doi/ abs/10.1177/0093854812437919

Brown, N., Gudjonsson, G., \& Connor, P. (2011). Suggestibility and fetal alcohol spectrum disorders: I'll tell you anything you want to hear. Journal of Psychiatry Law, 39(1), 39-72. Retrieved from https://journals.sagepub.com/doi/ abs/10.1177/009318531103900103

Carpenter, B., Blackburn, C., \& Egerton, J. (2014). A brief introduction to fetal alcohol spectrum disorders. In B. Carpenter, C. Blackburn, \& J. Egerton (Eds.), Fetal alcohol spectrum disorders: Interdisciplinary perspectives (pp. 3-13). Routledge.

Cheung, J., Timmins, J., \& Wright, C. (2015). Patterns and dynamics of alcohol consumption during pregnancy in a recent cohort of expectant mothers. Retrieved from https://superuhub.cwp.govt.nz/assets/documents/ Alcohol\%20and\%20Pregnancy\%20Research\%20 Report.pdf 
Chudley, A. (2018). Diagnosis of fetal alcohol spectrum disorder: Current practices and future considerations. Biochemistry and Cell Biology, 96(2), 231-236. Retrieved from https://www.ncbi.nlm.nih.gov/ pubmed/28746809

Clarren, S., Halliwell, C., Werk, C., Sebaldt, R., Petrie, A. Lilley, C., \& Cook, J. (2015). Using a common form for consistent collection and reporting of FASD data from across Canada: A feasibility study. Journal of Population Therapeutics and Clinical Pharmacology, 22(3). Retrieved from https://www.ncbi.nlm.nih.gov/pubmed/26567605

Connor, J., \& Casswell, S. (2012). Alcohol-related harm to others in New Zealand: evidence of the burden and gaps in knowledge. New Zealand Medical Journal, 125(1360), 11 - 27. Retrieved from https://www.nzma.org.nz/journal/ read-the-journal/all-issues/2010-2019/2012/vol-125no-1360/article-connor

Cook, J. L., Green, C. R., Lilley, C. M., Anderson, S. M., Baldwin, M. E., Chudley, A. E., ... Canada Fetal Alcohol Spectrum Disorder Research. (2016). Fetal alcohol spectrum disorder: a guideline for diagnosis across the lifespan. Canadian Medical Association Journal, 188(3), 191-197. Retrieved from https://www.ncbi.nlm.nih.gov/ pubmed/26668194

Crawford, A. (2018). Social cognition, executive functioning and IQ. What are the important influences on adaptive functioning in children with Fetal Alcohol Spectrum Disorder? (Unpublished doctoral thesis), University of Auckland. Retrieved from https://researchspace. auckland.ac.nz/handle/2292/37651

Durie, M. (2001). Mauri ora: The dynamics of Māori health. Auckland: Oxford University Press.

Egan, R., \& Craik, C. (2016). Taking action: Change and intervention. In J. Maidment \& R. Egan (Eds.), Practice skills in social work and welfare: More than just common sense (3rd ed., pp. 227-243). Allen \& Unwin.

Egerton, J. (2014). A step in time: Fetal alcohol spectrum disorders and transition to adulthood. In B. Carpenter, C. Blackburn, \& J. Egerton (Eds.), Fetal alcohol spectrum disorders: Interdisciplinary perspectives (pp. 141-157). Routledge.

Enns, L., \& Taylor, N. (2018). Factors predictive of a fetal alcohol spectrum disorder: Neuropsychological assessment. Child Neuropsychology, 24(2), 203225. Retrieved from https://www.ncbi.nlm.nih.gov/ pubmed/27830992

FASD Working Group. (2016). Taking Action on Fetal Alcohol Spectrum Disorder: 2016 - 2019: An Action Plan. Retrieved from https://www.health.govt.nz/system/files/ documents/publications/taking-action-on-fetal-alcoholspectrum-disorder-2016-to-2019.pdf

Fast, D. K., \& Conry, J. (2004). The challenge of fetal alcohol syndrome in the criminal legal system. Addiction Biology, 9(2), 161-166. https://doi.org/10.1080/1355621041000 1717042

Fast, D. K., \& Conry, J. (2009). Fetal alcohol spectrum disorders and the criminal justice system. Developmental Disabilities Research Reviews, 15(3), 250-257. https://doi-org.ezproxy.otago.ac.nz/10.1002/ddrr.66

Fast, D. K., Conry, J., \& Loock, C. A. (1999). Identifying fetal alcohol syndrome among youth in the criminal justice system. Journal of Developmental \& Behavioural Pediatrics, 20(5), 370-372. Retrieved from https://www.ncbi.nlm.nih.gov/pubmed/10533996
Fitzgerald, T. (2015). Neurodisabilities and youth offending. Court in the Act, (71), 18-21. Retrieved from http://www.districtcourts.govt.nz/assets/Uploads/Courtin-the-Act/Court-in-the-Act-Issue-71.pdf

Fitzpatrick, J. P., Latimer, J., Olson, H. C., Carter, M., Oscar, J., Lucas, B. R., ... Elliott, E. J. (2017). Prevalence and profile of neurodevelopment and fetal alcohol spectrum disorder (FASD) amongst Australian Aboriginal children living in remote communities. Research in Developmental Disabilities, 65, 114-126. Retrieved from http://www.sciencedirect.com/science/article/pii/ S0891422217300975

Gibbs, A., Bagley, K., Badry, D., \& Gollner, V. (2020). Foetal alcohol spectrum disorder: Effective helping responses from social workers. International Social Work, 63(4), 496-509. https://doi.org/10.1177/0020872818804032

Gibbs, A., \& Sherwood, K. (2017). Putting fetal alcohol spectrum disorder (FASD) on the map in New Zealand: A review of health, social, political, justice and cultural developments. Psychiatry, Psychology and Law, 24(6), 825-842. https://doi.org/10.1080/13218719.2017.1315784

Gillen, P., \& Dubovsky, D. (2012). Towards developing a manual for residential treatment centres to support individuals with FASD and their families. [PowerPoint Slides]. Retrieved from https://docplayer.net/3296754Towards-developing-a-manual-for-residential-treatmentcenters-to-support-individuals-with-an-fasd-and-theirfamilies.html

Gralton, E. (2014). Foetal alcohol spectrum disorder (FASD)Its relevance to forensic adolescent services. Journal of Intellectual Disabilities and Offending Behaviour, 5(3), 124-137. Retrieved from https://www.deepdyve.com/ Ip/emerald-publishing/foetal-alcohol-spectrum-disorderfasd-its-relevance-to-forensic-E9uXa0Ppf2

Hughes, N., \& Peirse O’Byrne, K. (2016). Disabled inside: Neurodevelopmental impairments among young people in custody. Prison Service Journal (226), 14-21. Retrieved from https://www.crimeandjustice.org.uk/sites/ crimeandjustice.org.uk/files/PSJ\%20226\%20July\%20 2016.pdf

Hughes, N., Williams, H., Chitsabean, P., Davies, R., \& Mounce, L. (2012). Nobody made the connection: The prevalence of neurodisability in young people who offend. United Kingdom: Office of the Children's Commissioner. Retrieved from https://yjlc.uk/wp-content/ uploads/2015/03/Neurodisability_Report_FINAL UPDATED_01_11_12.pdf.

International Federation of Social Workers. (2014). Global definition of social work. Retrieved from https://www.ifsw. org/what-is-social-work/global-definition-of-social-work/

JustSpeak. (2012). Submission on Youth Crime Action Plan. Retrieved from https://www.occ.org.nz/assets/Uploads/ submissions/Youth-crime-action-plan.pdf

Killingley, J. (2014). Fetal alcohol spectrum disorders and criminal responsibility. In B. Carpenter, C. Blackburn, \& J. Egerton (Eds.), Fetal alcohol spectrum disorders: Interdisciplinary perspectives (pp. 199-206). Routledge.

Longstaffe, S., Chudley, A. E., Harvie, M. K., Markesteyn, T., Neault, D., \& Brown, T. (2018). The Manitoba Youth Justice Program: Empowering and supporting youth with FASD in conflict with the law. Biochemistry \& Cell Biology, 96(2), 260-266. Retrieved from http://search. ebscohost.com/login.aspx?direct=true $\& \mathrm{db}=a 9 h \& A N=129$ $007698 \&$ site $=$ ehost-live $\&$ scope $=$ site 
Lynch, N. (2016). Neurodisability in the youth justice system in New Zealand: How vulnerability intersects with justice. 2016 Neurodisabilities Forum. Retrieved from https://ssrn.com/abstract=2869502

Malbin, D. (2002). Fetal alcohol spectrum disorders: Trying differently rather than trying harder (2nd ed.). Beaverton, OR: FASCETS.

Mallard, S. R., Connor, J. L., \& Houghton, L. A. (2013). Maternal factors associated with heavy periconceptional alcohol intake and drinking following pregnancy recognition: A post-partum survey of New Zealand women. Drug and Alcohol Review, 32(4), 389-397. https://doi.org/10.1111/dar.12024

Mattson, S. N., Crocker, N., \& Nguyen, T. T. (2011). Fetal alcohol spectrum disorders: Neuropsychological and behavioral features. Neuropsychology Review, 21(2), 81-101. Retrieved from https://www.ncbi.nlm.nih.gov/ pubmed/21503685

Matua Raki. (2019). FASD: Essential strategies: A resource for frontline professionals. Retrieved from https://www.matuaraki.org.nz/uploads/files/resourceassets/FASD-EssentialStrategiesFramework-\%20web.pdf

May, P. A., Chambers, C. D., Kalberg, W. O., Zellner, J., Feldman, H., Buckley, D., ... Hoyme, H. E. (2018). Prevalence of fetal alcohol spectrum disorders in 4 US communities. JAMA, 319(5), 474-482. https://doi.org/10.1001/jama.2017.21896

Mclver, L. (2010a). Fetal alcohol spectrum disorder in the Youth Court: Part 2. Court in the Act, (51), 6-8. Retrieved from http://www.districtcourts.govt.nz/youthcourt/newsletters/court-in-the-act/

Mclver, L. (2010b). Fetal alcohol spectrum disorder in the Youth Court: Undiagnosed and unrecognised. Court in the Act, (50), 12-13. Retrieved from http://www.districtcourts.govt.nz/youth-court/newsletters/ court-in-the-act/

McQuire, C., Mukherjee, R., Hurt, L., Higgins, A., Greene, G., Farewell, D., Kemp, A., \& Paranjothy, S. (2019). Screening prevalence of fetal alcohol spectrum disorders in a region of the United Kingdom: A population-based birth-cohort study. Preventive Medicine, 118, 344-351. Retrieved from http://www.sciencedirect.com/science/ article/pii/S0091743518303323

Ontario Centre of Excellence for Child and Youth Mental Health. (2016). Best practices to support youth with FASD in residential settings. Evidence In-Sight. Retrieved from http://www.excellenceforchildandyouth. ca/resource-hub/best-practices-support-youth-fasdresidential-settings

Payne, J., France, K., Henley, N., D'Antoine, H., Bartu, A., O'Leary, C., ... \& Bower, C. (2011). Changes in health professionals' knowledge, attitudes and practice following provision of educational resources about prevention of prenatal alcohol exposure and fetal alcohol spectrum disorder. Paediatric and Perinatal Epidemiology, 25(4), 316-327. https://doi.org/10.1111/ j.1365-3016.2011.01197.x

Pei, J., Leung, W. S. W., Jampolsky, F., \& Alsbury, B. (2016). Experiences in the Canadian criminal justice system for individuals with fetal alcohol spectrum disorders: Double jeopardy? Canadian Journal of Criminology \& Criminal Justice, 58(1), 56-86. Retrieved from http://search. ebscohost.com/login.aspx?direct=true $\& \mathrm{db}=a 9 h \& A N=112$ 352455\&site $=$ ehost-live\&scope $=$ site
Popova, S., Lange, S., Bekmuradov, D., Mihic, A., \& Rehm, J. (2011). Fetal alcohol spectrum disorder prevalence estimates in correctional systems: A systematic literature review. Canadian Journal of Public Health/ Revue Canadienne de Sante'e Publique, 102(5), 336-340. http://www.jstor.org.ezproxy.otago.ac.nz/ stable/41995627

Rogan, C., \& Crawford, A. (2014). Building a community of care through diagnosis of fetal alcohol spectrum disorders in Aotearoa New Zealand. In B. Carpenter, C. Blackburn, \& J. Egerton (Eds.), Fetal alcohol spectrum disorders: Interdisciplinary perspectives (pp. 174-182). Routledge.

Saleebey, D. (1997). The strengths approach to practice. In D. Saleebey (Ed.), The strengths perspective in social work practice (2nd ed., pp. 49-57). Longman.

Salmon, J. (2014). The experiences and views of individuals with fetal alcohol spectrum disorder: A New Zealand approach. Nova Science Publishers.

Streissguth, A. P., Bookstein, F. L., Barr, H. M., Sampson, P. D., O'Malley, L., \& Young, J. K. (2004). Risk factors for adverse life outcomes in fetal alcohol syndrome and fetal alcohol effects. Journal of Developmental \& Behavioural Pediatrics, 25(4), 228-238.

Streissguth, A. P., \& O’Malley, K. (2000). Neuropsychiatric Implications and long term consequences of fetal alcohol spectrum disorders. Seminars in Child Neuropsychiatry, 5(3), 177-190. Retrieved from https://www.ncbi.nlm.nih. gov/pubmed/11291013

Tāngata Whenua Voices in Social Work. (2016). Kaitiakitanga Framework. Retrieved from https://swrb. govt.nz/about-us/news-and-publications/publications/

Tavioni-Pittman, M., \& Marsh, C. (2017). Neurodisability and therapeutic justice. Neurodisability and Therapeutic Justice Symposium. Retrieved from https://www.adls. org.nz/for-the-profession/news-and-opinion/2017/7/21/ symposium-on-\%E2\%80\%9Cneurodisability-andtherapeutic-jurisprudence\%E2\%80\%9D/

Tough, S. C., Clarke, M., \& Hicks, M. (2003). Knowledge and attitudes of Canadian psychiatrists regarding fetal alcohol spectrum disorders. The Canadian Child and Adolescent Psychiatry Review [La revue canadienne de psychiatrie de l'enfant et de l'adolescent], 12(3), 64-71. Retrieved from https://www.ncbi.nlm.nih.gov/ pubmed/19030527

Townsend, C., Hammill, J., \& White, P. (2015). Fetal alcoho disorder, disability and the criminal justice system. Indigenous Law Bulletin, 8(17), 30-33. Retrieved from http://www.austlii.edu.au/au/journals/ILB/2015/19.pdf

Ungar, M. (2014). Working with children and youth with complex needs: 20 skills to build resilience. Routledge.

Walker, J. (2018, October). Barriers to engagement: Enabling full participation in the justice system for young people. Paper presented at the Justice for Young People Conference, Adelaide, Australia. Retrieved from http://www.districtcourts.govt.nz/youth-court/publications/ barriers-to-engagement-enabling-full-participation-in-thejustice-system-for-young-people/ 